\title{
Perfil Químico da Parede Celular e suas Implicações na Digestibilidade de Brachiaria brizantha e Brachiaria humidicola
}

\author{
Cláudio José F. Alves de Brito¹, Roberto Antonio Rodella², Francisco Carlos Deschamps ${ }^{3}$
}

\begin{abstract}
RESUMO - No presente trabalho foram determinadas a composição química e a digestibilidade de diversas frações de Brachiaria brizantha e Brachiaria humidicola, após 70 dias de crescimento. O delineamento experimental foi inteiramente casualizado com cinco repetições para cada espécie. As plantas coletadas foram subdivididas nas frações apical, mediana e basal para as folhas e mediana e basilar para caules, de acordo com sua localização. Foram determinadas as concentrações de fibra em detergente neutro (FDN), proteína bruta (PB), lignina, ácido p_cumárico, ácido ferúlico e açúcares neutros (glicose, xilose e arabinose) e a digestibilidade in situ após 48 horas de período de incubação ruminal. As diferentes frações das espécies estudadas apresentam distinta composição química, cujos efeitos são observados na digestibilidade. A B. brizantha apresentou maiores concentrações de FDN no caule e PB nas folhas. Isto resultou em coeficientes de digestibilidade maiores em relação à $B$. humidicola. A diferença de digestibilidade entre caule e folhas e nas frações mais velhas pode estar relacionada ao tipo de condensação da lignina presente nos tecidos. Evidências na concentração e na proporção dos ácidos p_cumárico e ferúlico sugerem esta relação. A concentração de ácidos fenólicos esteve relacionada com a digestibilidade da matéria seca e a lignina com a digestibilidade da FDN. A análise dos ácidos fenólicos pode se constituir em importante ferramenta para avaliar o grau de condensação da lignina na parede celular dos diferentes tecidos das plantas forrageiras. A concentração de açúcares neutros não apresentou um padrão definido na composição dos diferentes tecidos. A arabinose foi o único açúcar que apresentou relações com a digestibilidade da matéria seca e com a concentração de ácidos fenólicos.
\end{abstract}

Palavras-chave: ácidos fenólicos, carboidratos, forragens, lignina, parede celular vegetal

\section{Chemical Profile of Cell Wall and its Implications on Brachiaria brizantha and Brachiaria humidicola Digestibility}

\begin{abstract}
In the present paper the chemical composition and digestibility of several Brachiaria brizantha and Brachiaria humidicola fractions were determined after 70 days of growth. The experimental design was completely randomized with five replications for each specie. According to the position, the harvested plants were subdivided into top, median and bottom fractions for leaves and median and basal fractions for stems. The concentration of neutral detergent fiber (NDF), crude protein (CP), lignin, p_coumaric acid, ferulic acid, neutral sugars (glucose, xylose and arabinose) and in situ digestibility with 48-hour rumen digestion were determined. The several fractions of species studied showed different chemical composition, whose effects were observed in digestibility. $B$. brizantha recorded greater NDF concentration in stems and CP in leaves. This resulted in higher digestibility coefficients compared to $B$. humidicola. The digestibility differences between stem and leaves and in older fractions may be related to the type of lignin condensation present in tissues. The evidences found in p_coumaric and ferulic acid rates and concentrations suggest this association. The fenolic acid concentration was better related to dry matter digestibility, whereas lignin with NDF digestibility. This analysis may constitute an important tool to evaluate lignin condensation in cell wall of different forages. The neutral sugars showed no definite deposition pattern in a varied of tissues. Arabinose was the only sugar associated to dry matter digestibility and fenolic acid concentration.
\end{abstract}

Key Words: fenolic acids, carbohydrates, forage, lignin, plant cell wall

\section{Introdução}

O desempenho dos ruminantes está associado à qualidade da forragem ingerida e da interação desta com a biota ruminal no processo de digestão. A qualidade da forrageira passa a ser relevante, quando o teor de proteína bruta se encontra acima de $12 \%$ e coeficiente de digestibilidade da matéria seca é superior a 55\%. Estes valores não são facilmente encontrados em forrageiras tropicais, que, em compensação, apresentam elevada taxa de acumulação de matéria seca em relação às espécies temperadas

\footnotetext{
${ }^{1}$ Eng ${ }^{\circ}$-Agrônomo, Doutor em Botânica, Professor Titular, UNIANDRADE. Cx. Postal 623, CEP: 80.011-970, Curitiba, PR, Brasil. E.mail: cjbrito@hotmail.com

2 Eng ${ }^{0}$-Agrônomo, Doutor em Botânica, Professor Assistente-Doutor, UNESP. Cx. Postal 510, CEP: 18.618-000, Botucatu, SP, Brasil. E.mail: rodella@ibb.unesp.br

${ }^{3}$ Médico Veterinário, Doutor em Bioquímica, Pesquisador, EPAGRI S.A./UNIVALI. Cx. Postal 277, CEP: 88.301-970, Itajaí, SC, Brasil.

E.mail: xicodsc@hotmail.com. Autor para correspondência.
} 
(Laetsch, 1974; Bogdan, 1977). Entretanto, esta superioridade produtiva pode estar comprometida pela redução dos teores de proteína bruta e digestibilidade, observada com a maturidade fisiológica. Neste caso, o espessamento da parede celular e o aumento da área ocupada pelo tecido vascular lignificado afetam a digestibilidade (Wilson, 1993; Wilson, 1997; Alves de Brito et al., 1999).

A lignina é um fator limitante para a degradação da parede celular (Jung \& Vogel, 1986; Buxton \& Russell, 1988; Jung, 1989; Jung \& Deetz, 1993). A deposição de lignina aumenta com a maturação fisiológica e diminui a digestibilidade dos polissacarídeos estruturais pelos ruminantes (Kamstra et al., 1958; Terry \& Tilley, 1964; Nascimento Jr., 1974; Jung \& Vogel, 1986; Reeves, 1987; Hatfield, 1993; Burns et al., 1997; Deschamps, 1999). Esta relação negativa tem sido mais claramente observada em gramíneas tropicais (plantas $\mathrm{C}_{4}$ ) (Ford et al., 1979: Akin et al., 1983; Wilson et al., 1983).

A condensação dos chamados ácidos fenólicos leva a formação da lignina, agindo, portanto, como suas unidades precursoras. Akin et al. (1985) concluíram que a natureza dos compostos fenólicos presentes no parênquima e esclerênquima de caules de gramíneas é diferente. Além disso, a quantidade de compostos fenólicos presentes nos diferentes tecidos, tem sido relacionada com a digestibilidade (Akin et al., 1990). Tem-se relatado que os compostos fenólicos derivados da lignina (vanilina, ácido p_cumárico e ácido ferúlico), inibem a digestão da celulose e da hemicelulose por culturas puras ou mistas de microorganismos ruminais (Akin, 1982; Chesson et al., 1982; Varel \& Jung, 1986; Akin et al., 1988). Como a lignina está ligada covalentemente à hemicelulose, e não à celulose, esperar-se-ia que os efeitos negativos afetassem a primeira e não a segunda (Jung, 1989). Entretanto, a redução na digestibilidade da celulose pode acontecer como resultado da ação limitada das celulases sobre a celulose, porque os feixes de celulose se apresentam dispersos em uma matriz de hemicelulose e lignina.

Wilson (1976) estudou as variações da composição química e digestibilidade em folhas, com diferentes níveis de inserção no colmo, de Panicum maximum, em diversas idades. $\mathrm{O}$ autor constatou que a composição química e a digestibilidade variaram com o nível de inserção, apresentando as folhas superiores, concentração de lignina mais elevada que as inferiores.

No presente trabalho foram estudados os efeitos da concentração de fibra em detergente neutro, proteína bruta, ácido p_cumárico, ácido ferúlico e açúcares neutros (glicose, xilose e arabinose), sobre a digestão de folhas e caules de Brachiaria brizantha e Brachiaria humidicola.

\section{Material e Métodos}

Foram utilizadas folhas (lâminas e bainhas foliares) e caules de B. brizantha (Hochst. ex A. Rich.) Stapf e de B. humidicola (Rendle) Schweick. O experimento foi conduzido na Empresa Catarinense de Pesquisa e Extensão Agropecuária - EPAGRI S.A., Estação Experimental de Itajaí, Santa Catarina, Brasil (265'ㄴ' $28^{\prime \prime S}, 48^{\circ} 39^{\prime} 43^{\prime \prime} \mathrm{W}, 5$ m.s.m.). As mudas foram plantadas em vasos plásticos com capacidade para 10 litros, providos de areia esterilizada como suporte e dispostas em casa de vegetação, recebendo solução nutritiva de macro e micronutrientes por gotejamento automático.

Aos 70 dias após o corte de uniformização das parcelas (um total de cinco vasos), coletaram-se os indivíduos pertencentes às duas espécies. Cada planta foi dividida em três partes (terços apical, mediano e basilar). O terço apical correspondeu as folhas cortadas a partir do último nó superior visível do caule. Para a constituição dos terços mediano e basilar, seccionou-se o caule ao meio de sua extensão, separando-se manualmente as respectivas folhas presentes em cada um dos segmentos de caule. As amostras assim constituídas foram secas em estufa de ventilação forçada a $55^{\circ} \mathrm{C}$, até obtenção de peso constante. Em seguida, foram processados em moinho tipo Wiley dotado de peneira $2 \mathrm{~mm}$, quando destinado à digestão in situ, e $1 \mathrm{~mm}$ para as análises químicas.

O ensaio de digestão in situ e as determinação químicas realizadas nas amostras foram conduzidos nos laboratórios da EPAGRI S.A. - Estação Experimental de Itajaí.

A proteína bruta foi determinada pelo método Kjelhdahl - semi-micro descrito por Silva (1981). A fibra em detergente neutro (FDN) foi determinada pelo método de Van Soest, com as amostras submetidas à digestão em detergente neutro, por 40 minutos em autoclave $120^{\circ} \mathrm{C}$ (Deschamps, 1999). Para a lignina adotou-se o método descrito por Theander \& Westerlund (1986) e Hatfield et al. (1994), obtendose a chamada lignina de Klason (TAPPI - Método T222/os-74). Neste caso, a amostra previamente extraída em etanol $80 \%$ por 1 hora, é submetida a

R. Bras. Zootec., v.32, n.6, p.1835-1844, 2003 (Supl. 2) 
digestão em meio ácido $\left(12\right.$ moles $/ \mathrm{L}, 1$ hora $/ 30^{\circ} \mathrm{C}$, sendo posteriormente diluído para 0,4 moles/L e hidrolisada por 1 hora $/ 120^{\circ} \mathrm{C}$ ). Neste processo, os carboidratos são solubilizados restando lignina e cinzas não solubilizadas. Após a filtragem, o material retido no filtro é denominado de lignina de Klason. Ajustou-se o volume final do filtrado para $100 \mathrm{~mL}$, separando-se cerca de $2 \mathrm{~mL}$ para posterior análise dos açúcares neutros (glicose, xilose e arabinose) por CLAE (Cromatografia Líquida de Alta Eficiência). As condições do cromatógrafo envolveram o uso de uma coluna Bio-Rad HPX-87H, fase móvel 0,005 moles $/ \mathrm{L}$ de $\mathrm{H}_{2} \mathrm{SO}_{4}$, fluxo de $0,6 \mathrm{~mL} /$ minuto, sendo o volume de injeção de $20 u l$.

Para determinação de ácidos fenólicos, foi utilizado um método modificado a partir do proposto por Hartley \& Buchan (1979) e descrito por Deschamps (2002).

Para os ensaios de digestão ruminal foi adotada a técnica do saco de náilon, com tempo de incubação fixado em 48 horas, utilizando-se três bovinos dotados de cânula ruminal. Foi utilizado o delineamento experimental inteiramente casualizado, com cinco repetições para o ensaio de degradação da matéria seca, três repetições na determinação de FDN e duas repetições na proteína bruta. Foram adotadas parcelas subdivididas, considerando-se como tratamento principal as duas espécies e como tratamento secundário, os níveis de inserção. Os resultados expressos em porcentagem foram transformados em arcoseno, sendo as médias comparadas pelo teste de Tukey, em nível de 5\% de probabilidade do erro.

\section{Resultados e Discussão}

A concentração de FDN é uma medida interessante para se avaliar a participação da parede celular na composição dos tecidos. O espessamento da parede celular secundária observado com a maturação dos tecidos vegetais resulta no incremento da concentração da FDN em detrimento do conteúdo celular (Wilson, 1993; Wilson, 1997; Alves de Brito, 1999). Especialmente em gramíneas e pela natureza distinta de seus tecidos, o conteúdo de FDN é maior no caule em relação às folhas, o que também foi observado no presente trabalho (Tabela 1). Nas folhas, não houve diferença $(\mathrm{P}>0,05)$ no nível de inserção nem entre as duas espécies (Tabela 1). Isto significa que a relação do conteúdo celular com a parede é semelhante nas duas espécies, independente da localização da folha. No caule, a fração basal apresentou concentração de
FDN maior que a fração mediana, representando tecidos em diferentes estádios de maturação. Por outro lado, a concentração de FDN no caule da $B$. brizantha foi maior que a observada na B. humidicola. Na planta inteira, os teores de FDN não foram diferentes $(\mathrm{P}>0,05)$ (Tabela 1$)$. Nesse caso, a razão pode estar relacionada às diferenças relativamente pequenas na concentração de FDN para folhas e caule em ambas as espécies.

A concentração de PB foi maior nas folhas em relação ao caule, interferindo pouco a origem da fração (nível de inserção). Considerando a planta inteira, a $B$. brizantha apresentou teor de PB superior ao da $B$. humidicola.

Maiores concentrações de PB contribuem para o necessário aporte de $\mathrm{N}$ à biota ruminal e também para criar regiões mais susceptíveis a ação dos microrganismos (Merchen \& Bourquin, 1994). No presente estudo, as evidências são fortes para esta afirmativa, já que o coeficiente de correlação entre a digestibilidade da matéria seca e o teor de PB foi de 0,89 (Tabela 2). Isto poderia explicar em parte, também, porquê a $B$. brizantha, quando analisada inteira, apresentou coeficiente de digestibilidade maior que a B. humidicola. Pode ser observado que a digestibilidade foi menor na fração basal do caule que na mediana $(\mathrm{P}<0,05)$ (Tabela 1). Em parte, estas tendências já foram relatadas em estudos de cinética de digestão de vários alimentos para ruminantes, onde se estabeleceram coeficientes de correlação de 0,75 para teores de PB e degradabilidade efetiva da matéria seca (Deschamps, 1994). Em estudos com capim-elefante (P. purpureum), foi estabelecido que a concentração de FDN se correlaciona negativamente $(-0,88)$ com a digestibilidade da matéria seca (Deschamps, 1999), sendo o mesmo valor determinado no presente estudo.

Os teores médios de lignina tenderam a se incrementar no sentido apical/basal (Tabela 3). Considerando as condições experimentais do presente trabalho, é possível que a presença de tecidos em diversos estágios de crescimento na mesma amostra tenha contribuído para as médias não fossem diferentes entre si $(\mathrm{P}>0,05)$. As gramíneas, em geral, depositam maior quantidade de lignina, à medida que os tecidos que compõem as frações vão envelhecendo. Esta tendência não foi plenamente confirmada neste estudo, pelo menos em termos estatísticos $(\mathrm{P}>0,05)$ (Tabela 3). Aman (1993) havia revisado estudos onde foram relatados resultados semelhantes aos descritos anteriormente. 
Tabela 1 - Teores de fibra em detergente neutro, proteína bruta e digestibilidade de Brachiaria brizantha e $B$. humidicola, em três níveis de inserção da folha

Table 1 - Neutral detergent fiber, crude protein content and digestibility of Brachiaria brizantha and B. humidicola, at three levels of leaf insertion

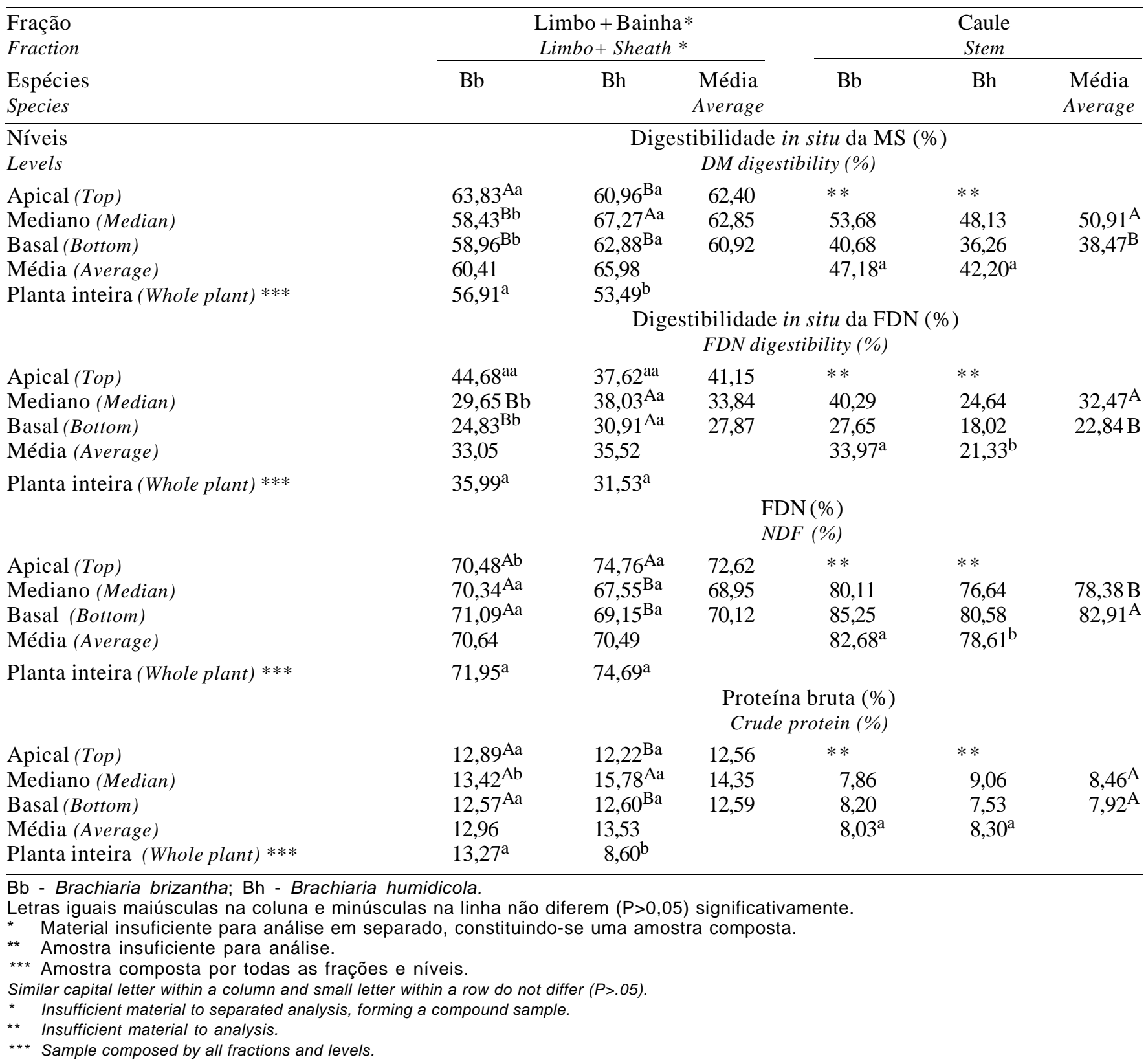

Em estudo com diferentes cultivares de capim elefante, observou-se que a concentração de lignina de Klason foi maior nas folhas do que no caule (Deschamps, 1999). Os efeitos negativos da presença de lignina na parede celular sobre a digestibilidade são maiores no caule. Isto é indicativo de que outros efeitos além da concentração de lignina estão associados à redução da digestibilidade (Deschamps, 1999). Maiores variações na concentração de lignina são observadas quando se comparam diferentes espécies de gramíneas e leguminosas e quando se observam os efeitos do envelhecimento dos tecidos vegetais (Aman, 1993; Jung et al., 1998; Deschamps, 1999). Vale lembrar que, nas condições do presente estudo, houve pouca participação de material morto nas amostras. Portanto, os tecidos estavam em plena atividade com os processo de deposição de lignina em franco andamento, mas não consolidado. O hábito de crescimento, o porte e o formato das folhas e caule são distintos de outras gramíneas como capim-elefante e cana-de-açúcar. Neste caso, a maturação fisiológica coincide com o aparecimento de material morto e com seu processo de lignificação completado.

Foi observada maior concentração de ácido

R. Bras. Zootec., v.32, n.6, p.1835-1844, 2003 (Supl. 2) 
Tabela 2 - Matriz de correlações para as variáveis estudadas envolvendo a caracterização química da parede celular da $B$. brizantha e $B$. humidicola

Table 2 - Correlation matrix for the studied variables involving chemical characterization of cell wall from $B$. brizantha and B. humidicola

\begin{tabular}{|c|c|c|c|c|c|c|c|c|c|c|}
\hline & Dig-MS & Dig-FDN & FDN & PB & Klason & P-cumárico & Ferúlico & Cumár:ferúl. & Glucose & Xilose \\
\hline Dig-FDN & $0,70 *$ & & & & & & & & & \\
\hline FDN & $-0,88^{*}$ & $-0,35$ & & & & & & & & \\
\hline PB & $0,89 *$ & 0,43 & $-0,95^{*}$ & & & & & & & \\
\hline Klason & $-0,40$ & $-0,74 *$ & 0,15 & $-0,15$ & & & & & & \\
\hline P_cumárico & $-0,81 *$ & $-0,24$ & $0,87^{*}$ & $-0,87^{*}$ & 0,11 & & & & & \\
\hline Ferúlico & $0,61 *$ & 0,01 & $-0,79 *$ & $0,76^{*}$ & 0,44 & $-0,71 *$ & & & & \\
\hline Cumár:ferúl. & $-0,81 *$ & $-0,18$ & $0,93 *$ & $-0,90 *$ & $-0,05$ & $0,96 *$ & $-0,85 *$ & & & \\
\hline Glucose & $-0,33$ & $-0,55^{*}$ & 0,11 & $-0,17$ & 0,22 & 0,04 & $-0,15$ & 0,08 & & \\
\hline Xilose & 0,17 & 0,26 & $-0,12$ & 0,32 & $-0,09$ & $-0,30$ & 0,13 & $-0,24$ & $-0,45$ & \\
\hline Arabinose & $0,59 *$ & $-0,03$ & $-0,78^{*}$ & $0,71^{*}$ & -004 & $-0,86^{*}$ & $0,57 *$ & $-0,84 *$ & 0,42 & 0,01 \\
\hline
\end{tabular}

* $(p<0,05)$; Dig_MS = digestibilidade da matéria seca; Dig_FDN = digestibilidade da fibra em deteregente neutro; FDN = fibra em deteregente neutro; Klason = lignina de Klason; P_cumárico = ácido p_cumárico; Cumár:ferul. = relação molar de ácido p_cumárico:ácido ferúlico. * $(p<.05) ;$ Dig_MS = dry matter digestibility; Dig_FDN = neutral detergent fiber digestibility; FDN = neutral detergent fiber; Klason = Klason lignin; $P \_c u m a ́ r i c o$ = P_coumaric acid; Cumar:ferul. = molar ration p_coumaric acid:ferulic acid.

p_cumárico no caule em relação às folhas, enquanto o ácido ferúlico está presente em maior concentração nas folhas (Tabela 4). Este fato é relevante, por sugerir que a dinâmica dos ácidos fenólicos precursores da lignina apresenta comportamento diferenciado em tecidos distintos de uma mesma planta.

Nas folhas, a concentração de ácido p_cumárico tendem a diminuir no sentido apical/basal, ao contrário da concentração de ácido ferúlico. Isto foi posteriormente confirmado quando se estabeleceu a relação p_cumárico:ferúlico que foi de 2,87 na apical, caindo para 1,82 na basal (Tabela 4). No caule estas tendências não se evidenciaram de modo que a concentração dos ácidos estudados, pelo menos em Brachiaria, não foi influenciada pela idade dos tecidos. Observa-se que a concentração de ácido p_cumárico foi superior nas amostras após a digestão ruminal. Comportamento inverso foi observado para o ácido ferúlico (Tabela 4). Isto se refletiu na relação p_cumárico:ferúlico, cujos valores após a digestão mais que duplicaram. Parte disto pode estar relacionado ao fato de o ácido ferúlico estar mais intimamente associado à arbinoxilana (Jung, 1989; Ralph \& Helm, 1993). Como a hemicelulose é substrato facilmente degradado pela biota ruminal, sua digestão implica na solubilização parcial dos complexos carboidrato:ácido ferúlico. Por outro lado a interação do ácido p_cumárico com os componentes mais condensados da lignina restringe o acesso dos sistemas enzimáticos da biota ruminal, restando assim, mais ácido p_cumárico nas amostras após a digestão. Portanto, é possível observar um caráter mais restritivo para a digestão dos tecidos, tendo como indicador a maior concentração de ácido p_cumárico. Esta afirmativa é consistente com o coeficiente de correlação de $-0,81(\mathrm{P}<0,05)$ entre a concentração de ácido p_cumárico e a digestibilidade da matéria seca (Tabela 2).

É descrito na literatura que o ácido ferúlico apresenta caráter inibitório para os processos de digestão da parede celular vegetal por parte da biota ruminal (Chesson et al., 1983; Varel \& Jung, 1986; Akin, 1988). Isto não foi confirmado neste estudo, já que o coeficiente de correlação entre ácido ferúlico e a digestibilidade foi de $0,61(\mathrm{P}<0,05)$, indicando que o ácido ferúlico não foi inibitório para o processo de digestão ruminal (Tabela 2).

À exceção da glicose nas folhas, a concentração média de açúcares neutros não apresentou diferenças mesmo analisando folhas e colmo em separado (Tabela 5). Parece que a dinâmica dos açúcares neutros não apresenta evidência para um padrão de deposição nas diversas frações dos tecidos estudados.

Assim, no sentido apical/basal das folhas, os incrementos na concentração de glicose e arabinose foram maiores em relação ao observado com a xilose. No caule, a média da concentração dos açucares estudados não apresentou diferenças entre as frações mediana e basal (Tabela 5), o que se justifica, em parte, pelo espessamento da parede celular, em função do envelhecimento dos tecidos (Wilson, 1997, Alves de Brito, 1997, Deschamps, 1999). Neste processo, a 
Tabela 3 - Teores lignina em Brachiaria brizantha e Brachiaria humidicola, em três níveis de inserção da folha, antes e após digestão in situ por $48 \mathrm{~h}$

Table 3 - Lignin content in Brachiaria brizantha and Brachiaria humidicola, at three levels of leaf insertion, before and after $48 \mathrm{~h}$ in situ digestion

\begin{tabular}{|c|c|c|c|c|c|c|}
\hline \multirow{2}{*}{$\begin{array}{l}\text { Fração } \\
\text { Fraction } \\
\text { Espécies } \\
\text { Species }\end{array}$} & \multicolumn{3}{|c|}{$\begin{array}{c}\text { Limbo + Bainha* } \\
\text { Limbo+ Sheath * }\end{array}$} & \multicolumn{3}{|c|}{$\begin{array}{l}\text { Caule } \\
\text { Stem }\end{array}$} \\
\hline & $\mathrm{Bb}$ & $\mathrm{Bh}$ & $\begin{array}{l}\text { Média } \\
\text { Average }\end{array}$ & $\mathrm{Bb}$ & $\mathrm{Bh}$ & $\begin{array}{l}\text { Média } \\
\text { Average }\end{array}$ \\
\hline $\begin{array}{l}\text { Níveis } \\
\text { Levels }\end{array}$ & \multicolumn{6}{|c|}{ Lignina de Klason $^{1}(\%)$} \\
\hline $\begin{array}{l}\text { Apical (Top) } \\
\text { Mediano (Median) } \\
\text { Basal (Bottom) } \\
\text { Média (Average) } \\
\text { Planta inteira (Whole plant) } * * *\end{array}$ & $\begin{array}{l}16,30^{\mathrm{Ba}} \\
17,40^{\mathrm{Ba}} \\
23,10^{\mathrm{Aa}} \\
18,93 \\
16,95^{\mathrm{a}}\end{array}$ & $\begin{array}{l}17,40^{\mathrm{Aa}} \\
16,50^{\mathrm{Aa}} \\
16,15^{\mathrm{Ab}} \\
16,68 \\
15,95^{\mathrm{a}}\end{array}$ & $\begin{array}{l}16,85 \\
16,95 \\
19,63\end{array}$ & $\begin{array}{l}* * \\
15,00 \\
18,70 \\
16,85^{\mathrm{a}}\end{array}$ & $\begin{array}{l}* * \\
18,25 \\
20,65 \\
19,45^{\mathrm{a}}\end{array}$ & $\begin{array}{l}16,63^{\mathrm{A}} \\
19,68^{\mathrm{A}}\end{array}$ \\
\hline & \multicolumn{6}{|c|}{$\begin{array}{c}\text { Lignina de Klason após a digestão ruminal (\%) } \\
\text { Klason lignin after rumen digestion }\end{array}$} \\
\hline Apical (Top) & 32,20 & 30,67 & $31,44^{\mathrm{A}}$ & $* *$ & $* *$ & \\
\hline Mediano (Median) & 32,03 & 34,33 & $33,18^{\mathrm{A}}$ & 26,87 & 27,97 & $27,42^{\mathrm{A}}$ \\
\hline Basal (Bottom) & 33,77 & 28,57 & $31,17^{\mathrm{A}}$ & 29,60 & 27,93 & $28,77^{\mathrm{A}}$ \\
\hline Média (Average) & $32,67^{\mathrm{a}}$ & $31,19^{\mathrm{a}}$ & & $28,24^{\mathrm{a}}$ & $27,95^{\mathrm{a}}$ & \\
\hline \multirow[t]{2}{*}{ Planta inteira (Whole plant) $* * *$} & $32,30^{\mathrm{a}}$ & $30,83^{\mathrm{a}}$ & & & & \\
\hline & \multicolumn{6}{|c|}{$\begin{array}{c}\operatorname{Lignina}^{2}(\%) \\
\text { Lignin }\end{array}$} \\
\hline Apical (Top) & $14,80^{\mathrm{Bb}}$ & $17,15^{\mathrm{Aa}}$ & 15,98 & $* *$ & $* *$ & \\
\hline Mediano (Median) & $15,65^{\mathrm{Ba}}$ & $16,15^{\mathrm{Aa}}$ & 15,90 & 14,20 & 18,05 & $16,13^{\mathrm{A}}$ \\
\hline Basal (Bottom) & $21,85^{\mathrm{Aa}}$ & $15,85^{\mathrm{Ab}}$ & 18,85 & 17,95 & 20,45 & $19,20^{\mathrm{A}}$ \\
\hline Média (Average) & 17,43 & 16,38 & & $16,08^{\mathrm{a}}$ & $19,25^{\mathrm{a}}$ & \\
\hline \multirow[t]{2}{*}{ Planta inteira (Whole plant) $* * *$} & $16,45^{\mathrm{a}}$ & $16,95^{\mathrm{a}}$ & & & & \\
\hline & \multicolumn{6}{|c|}{$\begin{array}{c}\text { Lignina após a digestão ruminal }(\%) \\
\text { Lignin after rumen digestion }\end{array}$} \\
\hline Apical (Top) & $30,20^{\mathrm{Aa}}$ & $25,17^{\mathrm{Ab}}$ & 27,69 & $* *$ & $* *$ & \\
\hline Mediano (Median) & $28,80^{\mathrm{Aa}}$ & $25,53 \mathrm{Aa}$ & 27,17 & $25,00^{\mathrm{Ba}}$ & $25,90^{\mathrm{Aa}}$ & 25,45 \\
\hline $\operatorname{Basal}($ Bottom) & $33,23^{\mathrm{Aa}}$ & $30,20^{\mathrm{Ab}}$ & 31,72 & $28,80^{\mathrm{Aa}}$ & $25,13^{\mathrm{Ab}}$ & 26,97 \\
\hline Média (Average) & 30,74 & 26,97 & & 26,90 & 25,52 & \\
\hline Planta inteira (Whole plant) $* * *$ & $24,67^{\mathrm{a}}$ & $28,03^{\mathrm{a}}$ & & & & \\
\hline
\end{tabular}

$\mathrm{Bb}$ - Brachiaria brizantha; Bh - Brachiaria humidicola.

Letras iguais maiúsculas na coluna e minúsculas na linha não diferem $(P>0,05)$ significativamente.

* Material insuficiente para análise em separado, constituindo-se uma amostra composta.

** Amostra insuficiente para análise.

***Amostra composta por todas as frações e níveis.

1 Lignina de Klason contém alguns elementos minerais e sílica além da lignina.

2 Lignina determinada após incineração do material, onde o remanescente é composto pelos minerais.

Similar capital letter within a column and small letter within a row do not differ $(P>.05)$.

* Insufficient material to separated analysis, forming a compound sample.

** Insufficient material to analysis.

*** Sample composed by all fractions and levels.

1 Klason Lignin, which holds silica and other minerals, beyond lignin.

Lignin determined after material incineration, where the residue is composed by minerals.

deposição de celulose se amplia refletindo no aumento da concentração de glicose. No caule, a função de sustentação e a natureza dos tecidos, implicam na presença de células com parede celular lignificada, mais espessada e rígida (Wilson, 1993). Interessante observar que a tendência para o comportamento da concentração da arabinose foi inversa nas folhas em relação ao caule. Esta tendência foi acompanhada pelos resultados determinados para o ácido ferúlico (Tabela 4). A ligação dos ácidos fenólicos com a hemicelulose se dá justamente através da ligação com a arabinose (Jung, 1989; Ralph \& Helm, 1993). Em parte, isto foi confirmado já que as concentrações médias tanto de ácido ferúlico quanto de arabinose foram menores no material após a digestão (Tabelas 4 e 5). Além disso, ambos apresentaram

R. Bras. Zootec., v.32, n.6, p.1835-1844, 2003 (Supl. 2) 
Perfil Químico da Parede Celular e suas Implicações na Digestibilidade de Brachiaria brizantha e...

Tabela 4 - Teores de ácidos fenólicos em Brachiaria brizantha e Brachiaria humidicola, em três níveis de inserção da folha, antes e após digestão in situ por 48 horas

Table 4 - Phenolic acids contents in Brachiaria brizantha and Brachiaria humidicola, at three levels of leaf insertion, before and after $48 \mathrm{~h}$ in situ digestion

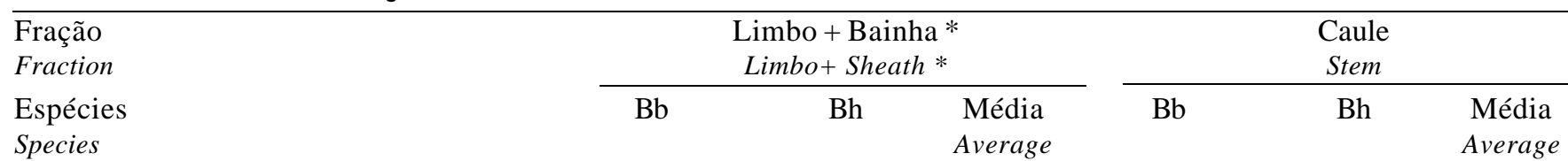

\section{Níveis}

Levels

Apical (Top)

Mediano (Median)

Basal (Bottom)

Média (Average)

Planta inteira (Whole plant) ***

Apical (Top)

Mediano (Median)

Basal (Bottom)

Média (Average)

Planta inteira (Whole plant) ***

\section{Apical (Top)}

Mediano (Median)

Basal (Bottom)

Média (Average)

Planta inteira (Whole plant) ***

Apical (Top)

Mediano (Median)

Basal (Bottom)

Média (Average)

Planta inteira (Whole plant) ***

Apical (Top)

Mediano (Median)

Basal (Bottom)

Média (Average)

Planta inteira (Whole plant) $* * *$

Apical (Top)

Mediano (Median)

Basal (Bottom)

Média (Average)

Planta inteira (Whole plant) $* * *$
12,05

11,64

11,53

$11,74^{\mathrm{a}}$

$13,77^{\mathrm{a}}$

10,96
8,42
8,02
$9,13^{\mathrm{a}}$
$10,15^{\mathrm{a}}$

Ácido p-cumárico após a digestão ruminal ( $\mu \mathrm{g} / \mathrm{mg} / \mathrm{MS})$ p_coumaric acid after rumen digestion

12,22
10,11
10,22
$10,79^{b}$
$15,53^{a}$

$12,04^{\mathrm{A}}$

$10,87^{\mathrm{B}}$

$10,88^{\mathrm{B}}$

15,56

15,80

$15,68^{\mathrm{A}}$

$10,79^{\mathrm{b}}$

15,51

$15,55^{\mathrm{a}}$

16,44

$16,12^{\mathrm{a}}$

$15,99^{\mathrm{A}}$

Ácido ferúlico $(\mu \mathrm{g} / \mathrm{mg} / \mathrm{MS})$

Ferulic acid

$3,52^{\mathrm{Ba}}$
$3,53^{\mathrm{Bb}}$
$4,43^{\mathrm{Aa}}$
3,82
$3,01^{\mathrm{a}}$

3,39

$3,25^{\mathrm{Bb}}$

$3,71^{\mathrm{Aa}}$

3,61

$* *$

$3,43^{\mathrm{Bb}}$

3,93

2,58

2,64

$2,61^{\mathrm{a}}$

2,96

2,99

3,46

$3,24^{\mathrm{a}}$

$2,97^{\mathrm{b}}$

$2,77^{\mathrm{A}}$

$2,81^{\mathrm{A}}$

Ácido ferúlico após a digestão ruminal ( $\mu \mathrm{g} / \mathrm{mg} / \mathrm{MS})$

Ferulic acid after rumen digestion

$\begin{array}{llllll}2,17 & 1,93 & 2,05^{\mathrm{A}} & * * & * * & \\ 2,07 & 1,95 & 2,01^{\mathrm{A}} & 1,38 & 1,77 & 1,57^{\mathrm{B}} \\ 1,97 & 1,81 & 1,89^{\mathrm{A}} & 1,46 & 1,85 & 1,65^{\mathrm{A}} \\ 2,07^{\mathrm{a}} & 1,89^{\mathrm{b}} & & 1,42^{\mathrm{b}} & 1,81^{\mathrm{a}} & \\ 1,85^{\mathrm{a}} & 1,89^{\mathrm{a}} & & & & \end{array}$

Relação ácido p-cumárico:Ácido ferúlico p_coumaric acid:Ferulic acid ratio

$\begin{array}{lllccc}3,11^{\mathrm{Aa}} & 2,63^{\mathrm{Ab}} & 2,87 & * * & * * & \\ 2,40^{\mathrm{Ba}} & 1,51^{\mathrm{Bb}} & 1,96 & 4,57 & 4,04 & 4,30^{\mathrm{A}} \\ 1,81^{\mathrm{Ca}} & 1,82^{\mathrm{Ba}} & 1,82 & 5,12 & 4,08 & 4,59^{\mathrm{A}} \\ 2,44 & 1,99 & & 4,84^{\mathrm{a}} & 4,06^{\mathrm{b}} & \\ 3,38^{\mathrm{a}} & 3,36^{\mathrm{a}} & & & & \end{array}$

Relação Acido p-cumárico/Ácido ferúlico após a digestão ruminal p_coumaric acid/Ferulic acid ratio after rumen digestion

\begin{tabular}{llllll}
$5,55^{\mathrm{Ab}}$ & $6,25^{\mathrm{Aa}}$ & 5,90 & $* *$ & $* *$ & \\
$5,61^{\mathrm{Aa}}$ & $5,18^{\mathrm{Cb}}$ & 5,39 & 11,29 & 8,82 & $10,06^{\mathrm{A}}$ \\
$5,82^{\mathrm{Aa}}$ & $5,65^{\mathrm{Ba}}$ & 5,74 & 10,68 & 8,91 & $9,79^{\mathrm{A}}$ \\
5,66 & 5,70 & & $10,99^{\mathrm{a}}$ & $8,87^{\mathrm{b}}$ & \\
$7,43^{\mathrm{b}}$ & $8,20^{\mathrm{a}}$ & & & & \\
\hline
\end{tabular}

$\mathrm{Bb}$ - Brachiaria brizantha; Bh - Brachiaria humidicola.

Letras iguais maiúsculas na coluna e minúsculas na linha não diferem $(P>0,05)$ significativamente.

* Material insuficiente para análise em separado, constituindo-se uma amostra composta.

** Amostra insuficiente para análise.

*** Amostra composta por todas as frações e níveis.

Similar capital letter within a column and small letter within a row do not differ $(P>.05)$.

* Insufficient material to separated analysis, forming a compound sample.

** Insufficient material to analysis.

*** Sample composed by all fractions and levels. 
Tabela 5 - Teores de açúcares neutros em Brachiaria brizantha e Brachiaria humidicola, em três níveis de inserção da folha, antes e após digestão in situ por 48 horas

Table 5 - Neutral sugars contents in Brachiaria brizantha and B. humidicola, at three levels of leaf insertion, before and after $48 h$ in situ digestion

\begin{tabular}{|c|c|c|c|c|c|}
\hline $\begin{array}{l}\text { Fração } \\
\text { Fraction }\end{array}$ & \multicolumn{2}{|c|}{$\begin{array}{l}\text { Limbo + Bainha* } \\
\text { Limbo+ Sheath * }\end{array}$} & \multicolumn{3}{|c|}{$\begin{array}{l}\text { Caule } \\
\text { Stem }\end{array}$} \\
\hline $\begin{array}{l}\text { Espécies } \\
\text { Species }\end{array}$ & $\mathrm{Bb}$ & $\begin{array}{l}\text { Média } \\
\text { Average }\end{array}$ & $\mathrm{Bb}$ & $\mathrm{Bh}$ & $\begin{array}{l}\text { Média } \\
\text { Average }\end{array}$ \\
\hline
\end{tabular}

Níveis

Levels

Apical (Top)

Mediano (Median)

Basal (Bottom)

Média (Average)

Planta inteira (Whole plant) ***

Apical (Top)

Mediano (Median)

Basal (Bottom)

Média (Average)

Planta inteira (Whole plant) $* * *$

Apical (Top)

Mediano (Median)

Basal (Bottom)

Média (Average)

Planta inteira (Whole plant) ***

Apical (Top)

Mediano (Median)

Basal (Bottom)

Média (Average)

Planta inteira (Whole plant) ***

136,90

143,90

107,75

$129,62^{\mathrm{a}}$

$231,90^{\mathrm{a}}$

107,70

153,55

37,30

$99,52^{\mathrm{a}}$

$107,70^{\mathrm{a}}$

17,30

21,80

24,80

$21,30^{\mathrm{a}}$

$28,45^{\mathrm{a}}$
Glucose ( $\mu \mathrm{g} / \mathrm{mg} / \mathrm{MS})$

$$
\text { Glucose }
$$

$\begin{array}{llll}264,35^{\mathrm{Ba}} & 246,60 & * * & * * \\ 374,50^{\mathrm{Aa}} & 312,18 & 236,10 & 460,25 \\ 384,90^{\mathrm{Aa}} & 350,23 & 392,45 & 336,35 \\ 341,25 & & 314,28^{\mathrm{a}} & 398,30^{\mathrm{a}}\end{array}$

$448,65^{\mathrm{a}}$

Glucose após a digestão ruminal $(\mu \mathrm{g} / \mathrm{mg} / \mathrm{MS})$

Glucose after rumen digestion

$\begin{array}{lllll}185,25 & 205,15^{\mathrm{A}} & * * & * * & \\ 230,15 & 276,20^{\mathrm{A}} & 349,55 & 275,65 & 312,60^{\mathrm{A}} \\ 194,10 & 222,83^{\mathrm{A}} & 399,00 & 392,20 & 395,60^{\mathrm{A}} \\ 203,17^{\mathrm{a}} & & 374,28^{\mathrm{a}} & 333,93^{\mathrm{a}} & \end{array}$

$285,15^{\mathrm{a}}$

Xilose $(\mu \mathrm{g} / \mathrm{mg} / \mathrm{MS}))$ Xylose

177,30

173,35

125,05

$158,57^{\mathrm{a}}$

$186,30^{\mathrm{b}}$

$130,98^{\mathrm{A}}$

$158,63^{\mathrm{A}} \quad 111,45$

161,65

$142,63^{\mathrm{A}}$

150,15

$183,25^{\mathrm{a}}$

$155,90^{\mathrm{A}}$

Xilose após a digestão ruminal ( $\mu \mathrm{g} / \mathrm{mg} / \mathrm{MS})$

Xylose after rumen digestion

97,00
121,05
90,00
$102,68^{\mathrm{a}}$
$105,95^{\mathrm{a}}$

$102,35^{\mathrm{A}}$
$137,30^{\mathrm{A}}$
$63,65^{\mathrm{A}}$

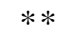

365,60

$63,65^{\mathrm{A}}$

101,90

$142,35^{\mathrm{a}}$

128,50

$155,65^{\mathrm{A}}$

$105,95^{\mathrm{a}}$

Arabinose $(\mu \mathrm{g} / \mathrm{mg} / \mathrm{MS})$

$$
\text { Arabinose }
$$

22,75
36,45
38,75
$32,65^{a}$
$24,85^{a}$

$20,03^{\mathrm{A}}$

$* *$

$29,13^{\mathrm{A}}$

7,75

11,10

$9,43^{\mathrm{a}}$

172,60

$150,55^{\mathrm{a}}$

$137,25^{\mathrm{A}}$

Arabinose após a digestão ruminal $(\mu \mathrm{g} / \mathrm{mg} / \mathrm{MS})$

Arabinose after rumen digestion

Apical (Top)

9,75

14,85

21,30

Basal (Bottom)

$15,30^{\mathrm{a}}$

Média (Average)

$12,70^{\mathrm{a}}$

$\begin{array}{rc}8,20^{\mathrm{A}} & * * \\ 11,04^{\mathrm{A}} & 10,55 \\ 16,35^{\mathrm{A}} & 9,80 \\ & 10,20^{\mathrm{a}}\end{array}$

11,75

13,85

$12,80^{\mathrm{a}}$
$11,15^{\mathrm{A}}$

$11,85^{\mathrm{A}}$
Planta inteira (Whole plant) ***

\footnotetext{
$\mathrm{Bb}$ - Brachiaria brizantha; Bh - Brachiaria humidicola.

* Material insuficiente para análise em separado, constituindo-se uma amostra composta.

** Amostra insuficiente para análise.

*** Amostra composta por todas as frações e níveis.

Similar capital letter within a column and small letter within a row do not differ $(P>.05)$.

* Insufficient material to separated analysis, forming a compound sample.

** Insufficient material to analysis.

*** Sample composed by all fractions and levels.
}

Letras iguais maiúsculas na coluna e minúsculas na linha não diferem $(P>0,05)$ significativamente. 
coeficiente de correlação positivo $(\mathrm{P}<0,05)$ com a digestibilidade da matéria seca $(0,61$ para ácido ferúlico: 0,59 para arabinose) (Tabela 2).

A concentração média de açúcares reduziu a metade após a digestão dos materiais nas folhas, o que não ocorreu no caule (Tabela 5). Isto sugere que o arranjo químico no caule é mais complexo, afetando mais a digestão do que o arranjo observado nas folhas. Então, mesmo com concentração de lignina semelhante no caule e nas folhas, os efeitos na digestão são distintos. Portanto, a natureza e a concentração dos ácidos fenólicos desempenham importante papel para a maior ou menor digestão da parede celular vegetal pelos ruminantes.

\section{Conclusões}

A digestibilidade e as concentrações de fibra em detergente neutro no caule e proteína bruta nas folhas é maior na $B$. brizantha em relação à $B$. humidicola .

Frações com a mesma concentração de lignina podem apresentar digestibilidade distinta. A presença de lignina na forma condensada, associada a células com parede celular mais espessa, constitui-se na maior barreira para a digestão dos tecidos no caule. Nas folhas, a maior proporção de ácido ferúlico sugere que a lignina seja menos condensada. Além disso, a maior digestão pode estar associada com células de parede secundária pouco desenvolvida, mais frequientes nas folhas do que nos caules.

Os ácidos fenólicos estudados tiveram maior relação com a digestibilidade da matéria seca, enquanto a concentração de lignina de Klason esteve mais relacionada com a digestibilidade da FDN.

A arabinose está relacionada à digestibilidade da matéria seca e à concentração de ácidos fenólicos.

\section{Literatura Citada}

AKIN, D.E. Forage cell wall degradation and p_coumaric, ferulic and sinapic acids. Agronomy Journal, v.74, p.424-428, 1982.

AKIN, D.E.; GOTTFRED, N.A.; HARTLEY, R.D. et al. Microspectrophotometry of phenolic compounds in bermudagrass cell wall in relation to rumen microbial digestion. Crop Science, v.30, p.396-401, 1990.

AKIN, D.E.; RIGSBY, L.L.; THEODOROU, M.K. et al. Population changes of fibrolytic rumen bacteria in the presence of phenolic acids and plant extracts. Animal Feed Science Technology, v.19, p.261-275, 1988.

AKIN, D.E.; WILLEMSE, T.M.; BARTON, F.E. Histochemical reactions, autofluorescence and rumen microbial degradation of tissues in untreated and delignified bermudagrass stems.
Crop Science, v.25, p.901-905, 1985.

AKIN, D.E.; WILSON, J.R.; WINDHAM, W.R. Site and rate of tissue digestion in leaves of $\mathrm{C}_{3}, \mathrm{C}_{4}$ and $\mathrm{C}_{3} / \mathrm{C}_{4}$ intermediate Panicum species. Crop Science, v.23, p.147-155, 1983.

ALVES DE BRITO, C.J.F. Organização estrutural e degradação in vitro de tecidos em Pennisetum purpureum Schum. (Poaceae). Curitiba: Universidade Federal do Paraná, 1997. 119p. Dissertação (Mestrado em Botânica) - Universidade Federal do Paraná, 1997.

ALVES DE BRITO, C.J.F.; RODELLA, R.A.; DESCHAMPS, F.C. et al. Anatomia quantitativa e degradação in vitro de tecidos em cultivares de capim-elefante (Pennisetum purpureum Schumach.). Revista Brasileira de Zootecnia, v.28, n.2, p.223-229, 1999.

AMAN, P. Composition and structure of cell wall polysaccharides in forages. In: JUNG, H.G.; BUXTON, D.R.; HATFIELD, R.D. et al. (Eds.) Forage cell wall structure and digestibility. Madison: Wisconsin:ASA/CSSA/SSSA, 1993. p.183-199.

BOGDAN, A.V. Tropical pastures and fodder plants. London: Logman, 1977. 475p.

BURNS, J.C.; POND, K.R.; FISHER, D.S. et al. Changes in forages quality, ingestive mastication and digesta kinetics resulting from switchgrass maturity. Journal of Animal Science, v.75, p.1368-1379, 1997.

BUXTON, D.R.; RUSSEL, J.R. Lignin constituents and cell wall digestibility of grass and legume stems. Crop Science, v.28, p.553-558, 1988.

CHESSON, A.; GORDON, A.H.; LOMAX, J.A. Substituent groups linked by alkali-labile bonds to arabinose and xylose residues of legume, grass, and cereal straw cell walls and their fate during digestion by rumen microorganisms. Journal of Science Food Agriculture, v.34, p.1330-1340, 1983.

CHESSON, A.; STEWART, C.S.; WALLACE, R.J. Influence of plant phenolic acids on growth and cellulolytic activity of rumen bacteria. Applied Environmental Microbiology, v.44, p.497-603, 1982.

DESCHAMPS, F.C. Degradabilidade ruminal da matéria seca e da proteína de alguns alimentos utilizáveis na alimentação de ruminantes. Revista da Sociedade Brasileira de Zootecnia, v.23, n.6, p.898-908, 1994.

DESCHAMPS, F.C. Implicações do período de crescimento na composição química e digestão dos tecidos de cultivares de capim elefante. Revista Brasileira de Zootecnia, v.28, n.6, p.1178-1189, 1999.

DESCHAMPS, F.C.; RAMOS, L.P. Método para a determinação de ácidos fenólicos na parede celular das forragens. Revista Brasileira de Zootecnia, v.31, n.4, p.1634-1639, 2002.

FORD, C.W.; MORRISON, I.M.; WILSON, J.R. Temperature effects on lignin, hemicellulose and cellulose in tropical and temperate grasses. Australian Journal of Agricultural Research, v.30, p.621-633, 1979.

HATFIELD, R.D. Cell wall polysaccharides interaction and degradability. In: JUNG, H.G.; BUXTON, D.R.; HATFIELD, R.D. et al. (Eds.) Forage cell wall structure and digestibility. Madison:Wisconsin:ASA/CSSA/SSSA, 1993. p.285-313.

HATFIELD, R.D.; JUNG, H.J.G.; RALPH, J. et al. A comparision of the insoluble residues produced by klason lignin and acid detergent lignin procedures. Journal of Science Food Agriculture, v.65, p.51-58, 1994.

HARTLEY, R.D.; BUCHAN, H. High-performance liquid 
chromatography of phenolic acids and aldehydes derived from plans or from the decomposition of organic matter in soil. Journal of Chromatography, v.180, p.139-143, 1979.

JUNG, H.G. Forages lignins and their effects on fiber digestibility. Agronomy Journal, v.81, p.33-38, 1989.

JUNG, H.G.; VOGEL, K.P. Influence of lignin on digestibility of forage cell wall material. Journal of Animal Science, v.62, p.1703-1712, 1986.

JUNG, H.G.; DEETZ, D.A. Cell wall lignification and digestibility. In: JUNG, H.G.; BUXTON, D.R.; HATFIELD, R.D. et al. (Eds.) Forage cell wall structure and digestibility. Madison: Wisconsin:ASA/CSSA/SSSA, 1993. p.315-346.

JUNG, H.G.; MORRISON, T.A.; BUXTON, D.R. Degradability of cell wall polysaccharides in maize internodes during stalk development. Crop Science, v.38, p.1047-1051, 1998.

KAMSTRA, L.D.; MOXON, A.L.; BENTLEY, O.G. The effect of stage af maturity and lignification on the digestion of cellulose in foage plants by rumen microorganisms in vitro. Journal of Animal Science, v.17, p.199-208, 1958.

LAETSCH, W.M. The C4 syndrome: a structural analysis. Annual Review of Plant Physiology, v.25, p.27-52, 1974.

MERCHEN, N.R.; BOURQUIN, L.D. Process of digestion and factors influencing digestion of forage-based diets by ruminants. In: FAHEY Jr., G.C. (Ed.) Forage quality, evaluation and utilization. Madison, Wisconsin:ASA/ CSSA/SSSA, 1994. p.564-612.

MORRISON, T.A.; JUNG, H.G.; BUXTON, D.R. et al. Cell wall composition of maize internode of varying maturity. Crop Science, v.38, p.455-460, 1998.

NASCIMENTO JR., D. Comentários sobre métodos químicos para avaliação de forragens. Revista da Sociedade Brasileira de Zootecnia, v.3, p.233-244, 1974.

RALPH, J.; HELM, R.F. Lignin/hydroxycinnamic acid/ polisaccharide complexes: Synthetic models for regiochemical characterization. In: JUNG, H.G.; BUXTON, D.R.; HATFIELD, R.D. et al. (Eds.) Forage cell wall structure and digestibility. Madison: Wisconsin:ASA/CSSA/SSSA, 1993. p.201-246.
REEVES, J.B. Lignin and fiber composition changes in forages over a growing season and their effects on in vitro digestibility. Journal of Dairy Science, v.70, p.1583-1594, 1987.

SILVA, J.D. Análise de alimentos (Métodos químicos e biológicos). Viçosa, MG: Universidade Federal de Viçosa, 1981. $166 \mathrm{p}$.

TERRY, R.A.; TILLEY, J.M.A. The indigestibility of the leaves and stems of perennial ryegrass, cocksfoot, timothy, tall fescue, lucerne and sainfoin as measured by in vitro procedure. Journal of British Grassland Society, v.19, p.362-372, 1964.

THEANDER, O.; WESTERLUND, E. Studies on dietary fiber. 3. Improved procedures for analysis of dietary fiber. Journal of Agricultural Food Chemistry, v.34, p.330-336, 1986.

VAREL, V.H.; JUNG, H.G. Influence of forage phenolics on ruminal fibrolytic bacteria and in vitro fiber degradation. Applied Environmental Microbiology, v.52, p.275-280, 1986 .

WILSON, J.R. Variation of leaf characteristics with level of insertion on a grass tiller. II. Anatomy. Australian Journal of Agricultural Research, v.27, p.355-364, 1976.

WILSON, J.R. Organization of forage plant tissues. In: JUNG, H.G.; BUXTON, D.R.; HATFIELD, R.D. et al. (Eds.) Forage cell wall structure and digestibility. Madison: ASA/CSSA/SSSA, 1993. p.1-32.

WILSON, J.R. Structural and anatomical traits of forage influencing their nutritive value for ruminants. In: SIMPÓSIO INTERNACIONAL SOBRE PRODUÇÃO ANIMAL EM PASTEJO, 1997, Viçosa, MG. Anais... Viçosa, MG: Universidade Federal de Viçosa, 1997. p.173-208.

WILSON, J.R.; BROWN, R.H.; WINDHAM, W.R. Influence of leaf anatomy on the dry matter digestibility of $\mathrm{C}_{3}, \mathrm{C}_{4}$ and $\mathrm{C}_{3} /$ $\mathrm{C}_{4}$ intermediate types of Panicum species. Crop Science, v.23, p.141-146, 1983. 